\title{
CONTRIBUIÇÕES AOS ESTUDOS DA QUESTÃO AGRÁRIA NO PONTAL DO PARANAPANEMA
}

\section{CONTRIBUTIONS TO THE QUESTION OF AGRICULTURAL STUDIES IN THE PONTAL OF PARANAPANEMA}

\author{
Munir Jorge Felício \\ Prof. Dr. em Geografia, docente permanente no Programa de Mestrado em Meio Ambiente e \\ Desenvolvimento Regional - MMADRE Universidade do Oeste Paulista-UNOESTE \\ munir@unoeste.br
}

\begin{abstract}
Resumo
As complexas estratégias de sobrevivência interpostas pelo campesinato se contrastam com a ampla expansão do capital na agricultura cujo objetivo consiste em transformá-la numa indústria. Unir na mesma análise essas duas realidades é a iniciativa desse texto como forma de fazer emergir a questão agrária em pleno desenvolvimento no Pontal do Paranapanema. Trata-se de relação complexa entre o campesinato e o capital em que ambos se renovam simultânea e contraditoriamente pelo debate oriundo das interpretações e dos seus significados. Este texto almeja discutir sobre essa complexidade para ampliar a compreensão de que a questão agrária é questão estrutural gerada pelo avanço do capital na agricultura. Com isso ter condições para compreender de que maneira o capital se expande nesse território para se apropriar dos recursos naturais. Simultaneamente analisar também as estratégias elaboradas pelo campesinato que se desenvolve dentro do sistema capitalista sem ser parte dele e, contraditoriamente, também sendo parte dele.
\end{abstract}

Palavras-chave: Capital. Campesinato. Questão agrária. Sistema capitalista. Agricultura.

\begin{abstract}
The complex survival strategies used by the peasantry are contrasted with the wide expansion of capital in agriculture, whose aim is to turn it into industry. Joined in the same analysis of these two realities is the initiative of this text as a way to bring out the agrarian question, currently in full swing in the Pontal of Paranapanema region. It is a complex relationship, between the peasantry and the capital, where both are renewed simultaneously and contradictorily the debate arising from interpretations and their meanings. This text aims to discuss this complexity to increase the understanding that the land issue is a structural issue generated by the capital advance in agriculture. With this, we will be able to understand how capital expands in that territory to appropriate the natural resources. Also analyzed are the strategies developed by the peasantry that develop within the capitalist system without being part of it and, paradoxically, also being part of it.
\end{abstract}

Keywords: Capital. Peasantry. Agrarian question. Capitalist system. Agriculture. 


\section{Introdução}

Este texto almeja participar do debate atual sobre a complexidade da questão agrária que se expande com o entrelaçamento de elementos novos e antigos, dentre os quais, estão os diferentes fins e recriações do campesinato. Reúne diversos debates teóricos cujas discussões visam ampliar a compreensão sobre o intenso processo da expansão do capital na agricultura e as estratégias construídas pelo campesinato para se desenvolver dentro do sistema capitalista, não sendo parte dele. E, contrariamente, sendo parte dele ao discutir possíveis processos que se desenvolvem entre o campesinato e o capital como subalternidade e/ou resistência. Por conseguinte, o campesinato e o capital constituem-se nos elementos estruturantes da questão agrária, concebida por esse texto como questão estrutural, pois, o campesinato se (re) cria para lutar contra o capital.

Os debates teóricos serão propostos a partir das análises desenvolvidas por pesquisadores seminais e contemporâneos. Na primeira parte, serão estudadas as análises clássicas de Kautsky (1986) e de Luxemburg (1985) e as contemporâneas de Mazoyer e Roudart (1998) e Ploeg (2008). Na segunda parte averiguar as análises desenvolvidas a partir da realidade brasileira e na última parte tentar compreender o desenvolvimento da questão agrária que se encontra em pleno vigor no Pontal do Paranapanema.

\section{Análises clássicas e contemporâneas sobre a questão agrária}

Compreender a questão agrária há muito se constitui um dos maiores desafios para a pesquisa em qualquer área do conhecimento dada sua amplitude e complexidade, como também, pelas possíveis interpretações e significados que as análises fazem emergir. Trata-se do estudo das relações entre o capital e o campesinato constituindo modelos explicativos desenvolvidos com perspectivas distintas de superação ou de manutenção do sistema capitalista. O debate dessas compreensões é imprescindível como condição necessária ao proporcionar a melhor e mais qualificada aproximação da realidade. Dentre as análises seminais que estudaram o avanço do capital na agricultura se destacam as de Kautsky (1986) pela importância de suas abordagens e discussões e de Luxemburg (1985) que tenta explicar o processo total da acumulação do capital. Dentre as análises 
contemporâneas se destacam as de Mazoyer e Roudart (1998) por analisar a herança agrária da humanidade e Ploeg (2008) que estuda a recriação do campesinato e sua luta contra o processo de invisibilização que se desenvolve historicamente.

Para Kautsky (1986, p. 22) o avanço do capital na agricultura revoluciona de forma profunda as bases existenciais do campesinato "sem que se torne necessário o capital entrar diretamente na produção agrária", tanto que até hoje, em nenhuma etapa histórica do desenvolvimento da agricultura, o capital se interessou pela produção de alimentos de primeira necessidade. Essa produção é uma das características do campesinato como apontou Chayanov (1974). Para compreender o avanço do capitalismo na agricultura, Kautsky (1986) explica que esse desenvolvimento ocorreu obedecendo às leis próprias da agricultura e não as leis que comandavam o desenvolvimento do capital na indústria. Diante dessas constatações, Kautsky (1986) lança um verdadeiro desafio. Contribuir com algumas respostas a esse desafio é um dos objetivos das presentes reflexões. O desafio empreendido por Kautsky (1986) consiste em

\footnotetext{
Examinar todas as transformações que sofre a agricultura nas várias fases do modo de produção capitalista. Devemos verificar se o capital se apodera da agricultura, como o faz, se a revoluciona, se torna insustentável as velhas formas de produção e propriedade e se acarreta ou não a necessidade de novas formas (KAUTSKY, 1986, p. 15).
}

Ao descrever o jeito camponês de fazer agricultura Kaustky (1986, p.17) demonstra com riqueza de detalhes "a família camponesa medieval". Além de possuir a terra, todo contingente familiar trabalhava, em conjunto, desenvolvendo uma produção tipicamente de subsistência e quase não vendia seus produtos para o mercado. Ao manter a produção familiar ia desenvolvendo sua própria tecnologia com a qual produzia tudo o que era necessário desde vestimentas, ferramentas, móveis, etc.

A produtividade tecnológica do campesinato proporcionou ampliar sua independência em relação ao mercado e, simultaneamente, impulsionou seu protagonismo e autonomia se constituindo as únicas forças políticas capaz de se levantar e montar barreiras como forma de colocar limites ao avanço do capital na agricultura. Avanço esse constituído por meios mais diversos possíveis, principalmente com o avanço industrial, como explica Kautsky (1986),

O desenvolvimento da indústria e do comércio, no entanto, geraram a demanda de novos produtos na cidade, demanda que a indústria agrícola era incapaz de satisfazer; esses produtos, a exemplo das ferramentas novas e mais perfeitas, também começaram a invadir o campo em ritmo crescente, na 
E, mais,

medida em que crescia o intercambio entre a cidade e o campo (KAUTSKY, 1986, p. 18).

É somente com o advento da indústria capitalista que se revela a regressão da indústria agrícola caseira de subsistência. Somente o sistema de comunicações, com suas ferrovias, correios e jornais, vai ser capaz de levar as novas ideias e produtos da cidade para os rincões mais afastados da zona rural, e colocar sob o domínio desse processo tanto as cercanias da cidade quanto a população toda do campo (KAUTSKY, 1986, p. 19).

A revolução industrial impulsionou o desenvolvimento de novas tecnologias na produção de equipamentos e insumos agrícola transformando o modo camponês de fazer agricultura e alterando de maneira radical as relações sociais da família e da aldeia camponesa. Paulatinamente a produção de subsistência vai sendo substituída pela produção empresarial visando atender as demandas urbanas cada vez mais intensas e exigentes. Por conseguinte, o avanço do capital na agricultura impôs ao campesinato a perda e o controle dos seus meios de produção como a terra e os seus equipamentos. Surge, então, o grande estabelecimento agrícola para a produção e fornecimento de matérias-primas para abastecer a indústria e o campesinato será importante na medida em que produzir alimentos de primeira necessidade - carne e grãos - suficientes para abastecer a população trabalhadora urbana.

O processo de substituição da produção de subsistência para a produção empresarial, apesar de ter seu inicio na Idade Média, fora impulsionado pelo modo de produção capitalista alterando de forma profunda as relações sociais, como esclarece Kautsky:

Esse processo ainda não chegou ao fim; ele prossegue e atinge progressivamente outras regiões e áreas cada vez mais extensas da produção agrária de subsistência, as quais convertem em regiões da produção mercantil. Ele amplia de várias formas a demanda de dinheiro entre os camponeses, substituindo o trabalho familiar pelo assalariado. Dessa maneira, o modo de produção capitalista, desenvolvido nas cidades, já é capaz de revolucionar completamente as bases existenciais do agricultor (tomado em sentido antigo) sem que se torne necessário o capital entrar diretamente na produção agrária, ou seja, antes mesmo de se formar qualquer oposição entre o grande e o pequeno estabelecimento agrícola. Contudo, a ação do capital não se restringe apenas a indústria. Uma vez fortalecido o suficiente, irá apoderar-se da agricultura (KAUTSKY, 1986, p. 15).

Para compreender como se deu a evolução do processo de substituição da produção de subsistência para a produção empresarial é importante recorrer às análises desenvolvidas por Luxemburg (1985), pela sua contribuição ao ampliar a compreensão das diversas implicações na agricultura, bem como entender de que maneira a 
agricultura de subsistência e a agricultura empresarial se desenvolvem a partir dessa transformação e em função dela.

O pleno desenvolvimento do capital depende, explica Luxemburg (1985), de sua capacidade de produzir de relações capitalistas e, simultaneamente, reproduzir no meio delas, as relações não capitalistas de produção, como condição para a apropriação de mais-valia, pois,

a produção capitalista não é, na verdade, a forma única e exclusiva existente de se produzir. Em todos os países capitalistas e mesmo nos altamente industrializados existem, além dos empreendimentos industriais e agrícolas de cunho capitalista, numerosos estabelecimentos congêneres mantendo uma linha simples de produção mercantil, [...] as mais diversas formas de economia paralelas, desde as comunistas primitivas até as feudais, agrícolas ou artesanais. Essas formas todas de sociedade ou de produção não só existem ou coexistem em perfeita harmonia com o capitalismo como também desenvolveram-se entre elas e o capital europeu um processo intenso e sui generis de trocas desde o início da era capitalista. [...] Teve assim de estabelecer-se, desde o início, uma relação de troca entre a produção capitalista e o meio não-capitalista, relação mediante a qual o capital encontraria a possibilidade de transformar sua mais-valia em ouro necessário à capitalização subseqüente, bem como de providenciar as mercadorias necessárias à expansão da própria produção, de garantir, enfim, o crescimento da força de trabalho proletarizada pela decomposição das formas não-capitalistas de produção (LUXEMBURG, 1985, p.334-335. Grifos no original).

A busca de um novo capital-dinheiro para garantir a remuneração do capital adiantado na produção de mercadoria, torna-se imprescindível para a produção capitalista e garante a sua reprodução com a qual impulsionará a acumulação almejada pelo capital, como explica Luxemburg (1985),

[...] enquanto se apresentar sob a forma de mercadoria, a mais-valia será inútil para o capitalista. Depois de produzida, portanto, ela precisa ser realizada ou transformada em sua forma pura de valor, ou seja, em dinheiro. Para que isso ocorra e o capitalista possa apropriar-se da mais-valia em forma de dinheiro, é necessário também que todo o seu capital adiantado abandone a forma de mercadoria, retornando ao capitalista sob forma de dinheiro. Somente então, quando se consegue que a mercadoria toda, em seu conjunto, seja alienada por dinheiro correspondente a seu valor, é que se alcança o objetivo da produção (LUXEMBURG, 1985, p. 12).

E, mais:

A produção capitalista não é uma produção voltada para fins de consumo, mas para a produção de valor. As relações de valor dominam totalmente o processo de produção, assim como o de reprodução. Produção capitalista não é produção de objetos de consumo, nem de mercadorias simplesmente, mas uma produção de mais-valia (LUXEMBURG, 1985, p. 14).

O questionamento que impulsionava a pesquisa de Luxemburg (1985) era o mesmo que outrora estava em Marx: “como é possível haver acumulação geral ou 
formação de um novo capital-dinheiro junto à classe capitalista?” (p. 345). Para Luxemburg "o esquema marxista da reprodução ampliada não consegue explicar-nos, pois, o processo de acumulação da maneira como ele realmente ocorre e como se impõe historicamente" (p. 239). A acumulação capitalista exige um mercado suplementar em outros extratos e nações não-capitalistas, como possibilidade de obter um novo capitaldinheiro diferente daquele que circula, no rodízio passando do bolso do capitalista para o bolso do proletariado e vice-versa:

A questão é, pois, a seguinte: O capital social total obtém constantemente e sob a forma de dinheiro um lucro total que, para fins de acumulação total, é obrigado a crescer constantemente. Como poderá crescer, então, essa soma, se as partes constituintes nada mais fazem senão um rodízio, passando de um bolso para outro? (LUEXEMBURG, 1985, p. 344).

Essa inovação é questão imprescindível para acumulação do capital por duas razões: primeira porque "acumular capital não significa apenas produzir quantidades cada vez maiores de mercadorias; significa antes transformar quantidades cada vez maiores de mercadorias em dinheiro" (LUXEMBURG, 1985, p. 343) e, segundo que “jamais houve, nem mesmo existe hoje, país algum em que só haja produção capitalista, ou só existam capitalistas e trabalhadores assalariados" (LUXEMBURG, 1985, p. 338). Por isso a (re) criação do campesinato contribui, de certa forma, com a expansão e o fortalecimento do capital, principalmente pelo uso da mão de obra familiar, tipicamente camponesa, ampliando a compreensão de que a questão agrária é uma questão da e na estrutura do sistema capitalista e, por conseguinte, a produção capitalista de relações não-capitalistas de produção atende ao "próprio caráter da produção capitalista que exclui, além do mais, a produção dos meios de produção que se restrinja ao modo capitalista” (p. 245). Luxemburg enfatiza que:

O papel que representou para a alimentação da grande massa operária industrial da Europa (ou seja, que essa alimentação representou como elemento do capital variável) o abastecimento camponês de cereais - do cereal que fora produzido de modo não-capitalista - para perceber quanto a acumulação capitalista está vinculada efetivamente, no tocante aos respectivos elementos materiais, a círculos não-capitalistas (LUXEMBURG, 1985, p. 245).

A importância das diversas formas de produção elucida Luxemburg (1985), não só é desejável, mas fundamental para o desenvolvimento do capital pela possibilidade em obter maiores e melhores meios de produção até atingir sua força total e, por intermédio dela impor seu dinamismo e conseguir organizar o globo sob sua égide. Até 
que isso aconteça a produção empresarial se desenvolverá atrelando e subsumindo as outras formas de produção, aumentando o dinamismo da questão agrária.

A agricultura feita pelo campesinato constitui numa das formas não-capitalista de produção por caracterizar-se pela multidiversidade, cuja economia consiste num sistema no qual se articulam a terra, o trabalho e os meios de produção organizados em função do processo de desenvolvimento familiar. Trata-se, portanto, de estratégias para a sobrevivência familiar como forma de driblar e escapar da asfixia do capitalismo como demonstrarão, a seguir, as análises de Mazoyer e Roudart (1998) e Ploeg (2008).

Para Mazoyer e Roudart (1998) a multidiversidade consiste na herança agrária da humanidade. Essa herança como tradição familiar foi passando e se aprimorando de uma geração para outra. Trata-se das inúmeras formas desenvolvidas pelo campesinato e, por intermédio delas, continua construindo, atualmente, o seu jeito de fazer agricultura, tanto que "permanecem predominantes e continuam a ocupar a maioria da população ativas dos países em vias de desenvolvimento" (MAZOYER e ROUDART, 1998, p. 12).

Esse jeito camponês de fazer agricultura contrasta com o jeito empresarial de fazer agricultura e, esse, está "muito longe de ter conquistado o mundo" (MAZOYER e ROUDART, 1998, p. 12). Ao detectar a multidiversidade e a uniformidade como formas distintas de fazer agricultura Mazoyer e Roudart constatam que

[...] entre essas agriculturas, as mais desfavorecidas e as menos produtivas são continuamente marginalizadas, mergulhadas na crise e eliminadas pela concorrência das agriculturas mais poderosas. Mas as que têm meios para se manter e para progredir ostentam uma riqueza de invenção insuspeita e continuam a desenvolver-se de acordo com as vias que lhes são próprias. É, por isso, um erro considerar essas agriculturas diferentes das dos países desenvolvidos, como tradicionais e imutáveis. Elas estão em transformação permanente e participam continuamente, também elas, na criação da modernidade. E é um outro erro (sic) conceber o desenvolvimento agrícola como a pura e simples substituição dessas agriculturas pela única que tem a reputação de moderna, a saber, a agricultura motorizada e mecanizada (MAZOYER e ROUDART, 1998, p. 12).

É exatamente essa agricultura motorizada e mecanizada a que se desenvolve para atender as exigências advindas da expansão do capital também percebida na Região do Pontal do Paranapanema como descreverá Origuéla (2011) mais adiante. Trata-se da reorganização analisada por Ploeg (2008) referente ao modos e meios de produção em que o capital procura sujeitar, por intermédio de seu controle, todas as formas de produção agrícola. Esse ordenamento consiste num ônus sobre as famílias camponesas, como uma forma de asfixia do capital sobre o campesinato. Esse modo de 
ordenamento dominante para a estruturação da produção agrícola foi denominado por Ploeg (2008) de Império:

Isto é, o Império corresponde aqui a uma rede verdadeiramente parasita (Feder, 1971). Os impérios alimentares desta natureza e estrutura são vampiros. Eles diferem, por assim dizer, os recursos locais até a exaustão, e transportam a riqueza obtida para outros lugares [...]. Através do Império, é possível explicar esta natureza, à primeira vista, fortemente enigmática da maldição dos recursos (PLOEG, 2008, p. 91. Grifos no original).

A agricultura camponesa desenvolvida pelo campesinato representa "acima de tudo, processos dinâmicos que se desenvolvem ao longo do tempo - em muitas direções diferentes e, por vezes, diametralmente opostas" (PLOEG, 2008, p. 39), procurando reduzir sua dependência e criar graus de autonomia. Esse tipo de fazer agricultura vem sendo denominada no Brasil, desde 1990, de agricultura familiar, como explica Neves (1995; 2007).

A agricultura capitalista consiste num modelo específico que interliga "atividades produtivas e distributivas já existentes, sendo estas, ao mesmo tempo, submetidas a um controle centralizado (a uma nova cúpula) e a novos princípios orientadores" (PLOEG, 2008, p. 107. Grifos no original), ampliando um ambiente hostil cuja tendência é

\footnotetext{
ser onipresente e universal: ele se estende por muitos domínios da vida social e da vida natural e introduz formas de controle que afetam praticamente todos os lugares. O Império penetra nos mais ínfimos detalhes do mundo social e do mundo natural (afetando até a forma como os ramos de amoras silvestres crescem). Através dele, uma grande variedade de ligações, processos e resultados são especificados de forma rígida e não negociável (PLOEG, 2008, p. 287).
}

As análises de Ploeg (2008); Mazoyer e Roudart (1998); Kautsky (1986) e Luxemburg (1985) proporcionaram conhecer o debate histórico sobre a complexidade da questão agrária estudada a partir das discussões em que se defrontam as diversas análises desenvolvidas com diferentes concepções. À medida que essas discussões se intensificam, vão emergindo as condições indispensáveis para se desvendar as razões e os motivos dos modelos explicativos dentro das análises, tais como: os referenciais teóricos, as ideologias, as intencionalidades e as opções políticas, entre outros. Esse mesmo debate também vem se estabelecendo no Brasil como será visto a seguir. 


\section{O desenvolvimento territorial e os embates entre o capital e o campesinato}

Para ampliar a compreensão sobre o desenvolvimento da questão agrária no Pontal do Paranapanema é importante conhecer as análises com abordagens em escala nacional. Nelas são destacadas temáticas como: as resistências históricas do campesinato, os modelos de desenvolvimento territorial, as políticas públicas implementadas devido as lutas sociais dentre as quais a luta pela Reforma Agrária ganha importância pelos enfrentamentos sangrentos, entre outras. Dentre os teóricos que trabalharam essas temáticas se destacam pela importância de suas construções analíticas: Navarro (2005; 2008); Martins (2004); Oliveira (2002; 2007) e Fernandes (2008).

Navarro (2005), ao interpretar a emergência das lutas sociais em áreas rurais nos últimos trinta anos, tendo o MST como referência, entende que houve mobilização sem emancipação. A não emancipação social e política dos pobres do campo devem-se ao desencontro entre o corpo diretivo da organização e sua base social principalmente quanto às interpretações referentes a produção do campesinato. Mesmo porque o assentado como um dos componentes do campesinato se constitui como "novo agricultor familiar", como entende Navarro (2008) e a agricultura familiar é a nova unidade produtiva do agronegócio por estar integrada na lógica capitalista, tecnificando seu processo produtivo e maximizando sua produção. Por conseguinte, entende Navarrro (2008) a distinção entre campesinato e agronegócio é totalmente inoportuna e inócua. Da mesma forma que a tentativa de diferenciação entre campesinato e agronegócio é muito mais teórica do que prática iludindo os movimentos camponeses que não conseguem nem emancipar e nem libertar, apenas alienar.

Para Martins (2004) a inutilidade das atuações dos movimentos camponeses, entre outras razões, deve-se aos grupos de mediação que introduziram nas lutas populares o seu próprio movimento social e o seu próprio hibridismo de classe. Os grupos de mediação de que fala Martins são dois: a CPT e o MST. Martins (2004, p. 21) afirma que:

MST e CPT perderam o controle do seu projeto de transformar a sociedade brasileira através da transformação da estrutura agrária, porque sua concepção maniqueísta e redutiva da política não lhes permite reconhecer-se como donatários políticos da vontade dos pobres da terra. Querer fazer uma revolução sem dela participar de maneira ativa, pública, responsável, criativa e política, nas condições possíveis e viáveis, é querer nada. Não se pode fazer política afirmando o partidário e negando o que é propriamente político. 
Para Martins (2004, p. 39-40) é inútil lutar pela Reforma Agrária, pois ela vem sendo feita pelo Estado desde 1964. O que está em disputa, na verdade, é a forma da Reforma, é o choque dos projetos históricos, é o embate das interpretações. E propõe entender essa disputa política revisando e revisitando dois temas históricos pendentes: a questão do trabalho livre (o fim da escravidão) e a questão agrária (1850 com o advento da Lei de Terras).

Os movimentos e as organizações populares, alerta Martins (2004), parecem engessados na moldura dos confrontos do período ditatorial (1964-1989) enquanto a sociedade e o Estado se transformaram rapidamente. Os grupos afundaram numa pratica própria do tempo da ditadura, a de desestabilizar o governo e precipitar crises institucionais perdendo o foco original que é a luta por Reforma Agrária, já que o "sujeito estrutural e histórico da reforma pretendida, que não é, fundamentalmente sem exclusivamente, o chamado sem-terra" (MARTINS, 2004, p. 40) e sim o agricultor familiar, por ter sido incorporado no modo de produção capitalista e não resistido à ele, como ocorre com o sem-terra e como ocorreu, no passado, com as lutas camponesas, como elucida Oliveira (2002) contra a estrutura fundiária.

A violência no campo no Brasil, segundo Oliveira (2002), não escolhe lugar ou tipo de vítima e o motivo principal está na estrutura latifundiária e na incapacidade do capital em absorver e gerar empregos para uma massa cada vez maior. A posição do Estado tem sido buscar a desarticulação como forma de tentar conter o avanço do campesinato, principalmente utilizando o seu poder de polícia, incrementando suas ações repressivas

O regime militar (1964-1989) conforme Oliveira (2002) comportou-se como poderoso leiloeiro por mais de vinte anos ao conviver, consentir e promover a distribuição de vasta quantidade das terras públicas entre latifundiários e empresários do Centro-Sul industrial. Foi o Estado o centro fundamental a partir de onde se consolidou como solda uma aliança entre a burguesia industrial e os latifundiários, como descreve Oliveira (2007, p. 123-124. Itálicos no original), mostrando os detalhes da

[...] promulgação do Decreto-Lei ${ }^{\circ} 1.179$, de 6/7/71, também pelo General Médici que instituiu o "Programa de Redistribuição de Terras e Estímulo à Agroindústria do Norte e Nordeste - PROTERRA - com o "objetivo de promover o mais fácil acesso do homem à terra, criar melhores condições de emprego, de mão-de-obra, de fomentar a agroindústria nas áreas de atuação da SUDAM e SUDENE. 
A leitura e a análise empreendida por Oliveira $(2002 ; 2007)$ contribui com os esclarecimentos do caráter rentista do capitalismo no Brasil compreendendo-o como aquele modelo de desenvolvimento que se faz de forma desigual e contraditória e que se apropria de uma estrutura fundiária extremamente concentrada. Diante desse avanço do capital o campesinato não tem alternativa a não ser organizar as ocupações coletivas de terras como forma de realizar a Reforma Agrária tantas vezes propalada pela elite política e negada pela força das armas.

Para Fernandes (2008) a presença e a atuação dos movimentos socioterritoriais constituem na criação de um modelo alternativo de desenvolvimento que contrasta com o modelo de desenvolvimento denominado de agronegócio. Enquanto esse modelo visa a comoditização de monocultura exportadora, o campesianto desenvolve seu potencial com a produção de alimentos para o mercado interno impulsionado mais pela diversidade do que pelo produtivismo, organizando os produtores em cooperativas e associações, utilizando de forma sustentável os recursos naturais e aumentando as desigualdades impulsionadora de conflitualidade, como explica Fernandes (2008),

\begin{abstract}
A conflitualidade gerada pelo capital em seu processo de territorialização, destrói e recria o campesinato, excluindo-o, subordinando-o, concentrando terra, aumentando as desigualdades. A conflitualidade gerada pelo campesinato em seu processo de territorialização destrói e recria o capital, ressocializando-se em sua formação autônoma, diminuindo as desigualdades, desconcentrando terra. Essa conflitualidade promove modelos distintos de desenvolvimento (FERNANDES, 2008, p. 180).
\end{abstract}

Este debate está presente nas discussões acadêmicas e dos movimentos sociais objetivando convencer ou derrotar oponentes. Ele está presente nas teorias, nos paradigmas, nos discursos promovendo disputa intelectual na qual se confrontam compreensões e leituras que indicam alternativas distintas. Ele está presente também nas temáticas tratadas pelos movimentos sociais, como o que ocorre, por exemplo, entre as perspectivas da Via Campesina.

A Via Campesina ${ }^{1}$ é um movimento internacional que coordena organizações camponesas em 56 países organizados em oito regiões: Europa, Este e Sudeste da Ásia, Sul da Ásia, América do Norte, Caribe, América Central, América do Sul e África, desde abril de 1992. Entre suas prioridades estão o desenvolvimento da solidariedade e a unidade dentro da diversidade objetivando promover relações econômicas de igualdade e de justiça social, a preservação do meio ambiente, a soberania alimentar, a produção agrícola sustentável, entre outros. Assim, nesta disputa intelectual dentro e 
fora da academia, confrontam-se compreensões e leituras contendo alternativas distintas, como evidenciado nas análises até aqui apresentadas.

A ocupação da terra, a resistência do campesinato e a produção no campo são indispensáveis politicamente, pois exigem respostas do Estado às situações de conflito, à constatação de necessidades coletivas e essas necessidades para tornarem-se políticas públicas precisam ser reconhecidas, problematizadas e assumidas por sujeitos coletivos. Essa materialização da luta pela terra se dá pela disputa por territórios num processo de desterritorialização do capital, ocupando os latifúndios e reterritorializando o campesinato. Por conseguinte, a implantação dos assentamentos de Reforma Agrária e a ampliação das possibilidades de acesso às políticas públicas são exigidas por um contingente populacional que, de outra forma, estaria excluída das perspectivas e das possibilidades para amparar as familias.

Hespanhol (1997) ao analisar as políticas públicas, modernização e crise da agricultura brasileira propõe um quadro geral visando compreender o desenvolvimento no decorrer das décadas de 1960 a 1980. Explica que, enquanto os pequenos produtores não conseguiram alterar sua base técnica produtiva sofrendo a exclusão do meio rural em virtude do caráter excludente e concentrador do processo modernizante, a oligarquia rural, os latifundiários usufruíram dos subsídios governamentais ampliando seu peso político e fortalecendo suas organizações.

Para Hespanhol (1997) os governos militares selaram um verdadeiro pacto com a classe dominante (burguesia urbana-industrial e aristocracia rural) em favor da chamada modernização da agricultura brasileira que se inicia na década de 1950, todavia torna-se expressiva a partir de meados da década seguinte. Até então a agricultura brasileira era rotulada de feudal em virtude da elevada concentração fundiária, da reduzida produtividade e da pequena articulação do setor com o mercado.

Entre 1965 e início dos anos 1980, no entender de Hespanhol (1997), o crédito rural subsidiado denominado Sistema Nacional de Crédito Rural - SNCR - constituiuse no principal instrumento de política agrícola. Através da oferta de crédito farto e barato, o governo procurava impulsionar a expansão do mercado interno transferindo recursos para modernizar o setor agrícola, visando aumentar o consumo de máquinas e insumos industriais e ampliar sua oferta de produtos exportáveis e de matéria prima para alimentar a indústria. 
Com o fim dos governos militares e a reabertura democrática consolidada com as eleições diretas, os presidentes eleitos persistiram com a defesa da estrutura fundiária facilitando o avanço do capital na agricultura por intermédio de um conjunto de medidas para que a produção agrícola ficasse submetida plenamente às leis econômicas do capitalismo, principalmente com os dois governos de Fernando Henrique Cardoso. Na sua sucessão o PT assume a presidência da república sem alterar significativamente os impulsos do governo anterior que visavam promover o desenvolvimento territorial rural como foram analisados por Sabourin (2007).

Trata-se do Programa Nacional de Fortalecimento da Agricultura Familiar Pronaf - entregue à Secretaria da Agricultura Familiar; do Programa de Desenvolvimento Sustentável dos Territórios Rurais - PDSTR - também denominado de Territórios da Cidadania entregue à Secretaria de Desenvolvimento Territorial e do Programa Nacional de Reforma Agrária entregue à Secretaria da Reforma Agrária. Conforme Sabourin (2007):

\footnotetext{
As três secretarias do MDA confiadas ao Partido dos Trabalhadores foram repartidas entre responsáveis e equipes vindos dos movimentos e organizações sindicais e profissionais, concorrentes entre elas ou ligadas a correntes diferentes do PT: a SRA à Contag, a SAF à Federação dos Trabalhadores da Agricultura Familiar (Fetraf), o Incra ao Movimento dos Trabalhadores Sem Terra (MST) e a SDT às cooperativas da agricultura familiar (SABOURIN, p. 2007, p. 7).
}

O Programa de Desenvolvimento Sustentável dos Territórios Rurais alcança a Região do Pontal do Paranapanema em 2008 se constituindo em um dos sessenta territórios que foram atendidos na primeira etapa do referido programa. Conforme informações no próprio site do programa ${ }^{2}$ estavam previstos investimentos na ordem de $\mathrm{R} \$$ 103,6 milhões de reais nesse território. Recursos destinados ao apoio para as atividades produtivas, fortalecimento da cidadania e acesso a direitos e recuperação e qualificação de infra-estrutura visando o desenvolvimento da agricultura regional. São ações com as quais o governo federal almeja reduzir as desigualdades regionais, levar direitos sociais a quem mais precisa e promover o desenvolvimento territorial regional.

Entre as análises ressaltando a importância das participações dos movimentos camponeses na espacialização e na territorialização da luta pela terra em escala nacional, destacam-se duas pela forma de elucidação dos dados e das informações: a publicação anual do caderno da Comissão Pastoral da Terra - CPT Conflitos no Campo 
Brasil e os diversos trabalhos publicados pelo Núcleo de Estudos, Pesquisa e Projetos de Reforma Agrária - NERA.

Nos Cadernos Conflitos no Campo Brasil são vinculadas análises que tratam de temáticas como: A Criminalização dos Movimentos Sociais; Os Levantes Indígenas contra a construção de hidrelétricas e Ocupações, Acampamentos e Assentamentos: o descompasso entre a luta pela terra e a política agrária do governo federal. Os movimentos camponeses fazem parte das resistências históricas dos pobres no campo denunciando o desenvolvimento de um processo contraditório na agricultura brasileira.

Entre os teóricos que têm se dedicado a esses estudos destacam-se as análises de Gohn (1997), nas quais ela investiga a gênese dos movimentos sociais e de que maneira se desenvolvem num determinado contexto histórico em que estão estabelecidas as relações de dominação-subordinação e fazem parte dos processos sociopolíticos e culturais da sociedade civil. Assim como os movimentos sociais criam um campo político, os movimentos camponeses procuram estabelecer um espaço político promovendo espacialidades com a disputa pelo controle do território. Para obter esse trunfo o campesinato ocupa terra, construindo espaços políticos e promovendo com um entrave à expansão do capital, pois, “o território é um trunfo particular, recurso e entrave, continente e conteúdo, tudo ao mesmo tempo. O território é o espaço político por excelência, o campo de ação dos trunfos”, como defende Raffestin (1993, p. 59).

As mobilizações sociais possuem a conquista do território como objeto de luta do campesinato, segundo Pedon (2009) e, por meio delas o campesinato se insere no quadro conflituoso da luta de classes oportunizando a construção de estruturas de embates contra o avanço do capital

a partir das agendas de luta por meio das quais são relacionados as ideologias, os propósitos, os interlocutores (as negociações com o Estado e com os agentes capitalistas) e as estratégias de ação (a exemplo das táticas de luta), e que, ao mesmo tempo, desempenham papel de instrumentos de conformação identitária (PEDON, 2009, 182-183).

Historicamente o campesinato regional se constitui a força política mais importante que tenta, por meio de suas estratégias, erguer barreiras com as quais estabelecer limites ao avanço do capital e se antepor frente às suas investidas para monopolizar o uso das terras agricultáveis. Entre as estratégias do campesinato para se manter incluído no sistema capitalista sem se submeter ao seu julgo se destacam a 
defesa dos seus meios de produção como a terra e os instrumentos de trabalho e o desenvolvimento do jeito camponês de fazer agricultura.

\section{Questão agrária e desenvolvimento regional no Pontal do Paranapanema}

A exemplo de Leite (1981) diversas análises demonstraram que ainda não terminou a expansão do capital nas terras do Pontal do Paranapanema, ainda que suas incursões evidenciem o quanto ele é violento e destrutivo por causa de suas leis de acumulação infinita, cujo atendimento só se dará com a liberdade de seus movimentos. $\mathrm{Na}$ medida em que o capital avança no território regional deixa um rastro de extinção e decadência tais como os inúmeros conflitos agrários, os estratagemas da grilagem de terra, as ardilosas disputas judiciais, o aniquilamento das matas nativas, da fauna e flora, a violência e a expulsão do campesinato, entre outras, como descreveu Leite (1981, p. 241) ao concluir que "na luta pelo domínio da terra ficou claro que vence sempre o poder econômico e político, [...]”, numa demonstração inequívoca do interesse do capital de se apropriar dos recursos naturais.

Frente às investidas do capital o campesinato regional levanta barreiras para impor limites à expansão capitalista, por intermédio das resistências, com mobilizações quando organiza a luta pela terra e pela Reforma Agrária, ocupando terras, montando acampamentos e implantando os assentamentos rurais e tantas outras ações dos movimentos socioterritoriais como foram analisadas por Pedon (2009); Feliciano (2006); Fernandes (1996); Felício (2011) entre outros.

A questão agrária que se desenvolve na Região do Pontal do Paranapanema é produto e processo do avanço do capital, cuja expansão engendra novas configurações e tenta impor seu modelo de desenvolvimento territorial mantendo e/ou aumentando a concentração de terras, renda e riqueza. Por tais razões, a questão agrária é questão estrutural do sistema capitalista cuja complexidade exige pesquisas e análises para poder conhecê-la e explicá-la.

As distinções da questão agrária nessa região emergem com a conflitualidade impulsionada pela disputa do território e dos significados. Do território, pelo enfrentamento entre o capital e o campesinato visando o seu controle e o seu domínio. Dos significados, pelo embate entre as concepções escolhidas pelos pesquisadores quando tentam compreender "todas as transformações que sofre a agricultura nas várias fases do modo de produção capitalista" como sugere Kautsky (1986, p. 15). 
Ainda persiste a necessidade de prosseguir as análises que se iniciaram com Kaustky (1986) principalmente no que se refere às transformações das relações sociais impulsionadas na agricultura, assim como as que ocorreram com o desenvolvimento de diversas estratégias construídas pelo campesinato regional no Pontal do Paranapanema descrito nas análises de Silveira (1990); Paulino (1997) e Origuéla (2011).

O entrelaçamento de elementos novos e antigos é constituinte essencial da complexidade da questão agrária, dentre os quais, se destacam os diferentes fins e recriações do campesinato de um lado, e, de outro, o contexto da reprodução do capital ao enaltecer a sua enorme produtividade. Esses elementos estão presentes nas análises de Origuéla (2011) ao apresentar as nuances da disputa territorial na região, uma vez que o capital ainda não se consolidou, apesar de seu interesse em ocupar esse território.

Origuéla (2011) chama a atenção para:

\begin{abstract}
O histórico de grilagem de terras, desmatamentos e pastagens do Pontal do Paranapanema, nos últimos anos, mais precisamente a partir de 2006, está sendo gradativamente substituído por plantações de cana-de-açúcar (THOMAS JUNIOR, 2009). [...] o agronegócio canavieiro é o mais expressivo e que tem disputado territórios com camponeses sem-terra e assentados. Estes, particularmente, têm arrecadado parte dos seus lotes para usinas de cana-de-açúcar da região, acreditando ser mais lucrativos arrendar do que produzir (Gonçalves, 2011) (ORIGUÉLA, 2011, p. 65-66).
\end{abstract}

Essa nova dinâmica da luta pela terra na região do Pontal do Paranapanema apresenta alguns componentes como: a) a morosidade do Estado na arrecadação de terras para fins de Reforma Agrária; b) os trabalhos de base e a formação de acampamentos com o objetivo de arregimentar famílias que sofrem nas periferias urbanas com o alto índice de desemprego, os pequenos arrendatários descapitalizados, meeiros e ex-funcionários de usinas sucroalcooleiras; c) o aumento da repressão judicial contra os militantes dos movimentos socioterritoriais, assentados e acampados; d) a reivindicação de terras públicas griladas que atualmente são destinadas para a monocultura canavieira.

As análises de Paulino (1997) visavam compreender a realidade agrária a partir da qual emergiram desdobramentos da apropriação capitalista da terra e as estratégias da exploração familiar no período de 1940 a 1996. As estratégias da luta contra a exclusão do acesso a terra e a manutenção da propriedade corresponde aos embates no território em que há a concentração fundiária característica do capitalismo rentista. Para Paulino (1997) os camponeses 
[...]não são resignados com esta conjuntura de expropriação, tampouco abdicam voluntariamente dos ganhos gerados pelo seu trabalho que são transferidos para mãos alheias. Trata-se da estrutura na qual estão inseridos, sendo este o preço pago pela recusa à proletarização. Neste sentido, caracterizam-se pela incessante modificação de estratégias visando preservar sua condição de produtor livre e, ao mesmo tempo, aumentar a apropriação dos resultados de seu trabalho. São exatamente estas mudanças de estratégias que refletem-se na organização interna destas unidades e que não podem ser entendidas, se desvinculadas de um contexto macro estrutural que interfere sobremaneira nestes rearranjos (PAULINO, 1997, p. 52).

O prosseguimento das análises de Paulino (1997) ganha importância por ampliar a compreensão das articulações do campesinato frente à expansão do capital na agricultura. Verificar de que maneira o campesinato luta para se desenvolver no sistema capitalista ao enfrentar os obstáculos que os excluem reinventando estratégias com dinamicidade para mantê-lo incluído. Historicamente o campesinato regional se recria por intermédio dessas estratégias para encontrar ou inventar formas de se inserirem na sociedade sem perder a sua condição camponesa.

Silveira (1990) estudou os processos articuladores da produção camponesa com o capital seja ele agrícola, comercial, industrial e financeiro no período histórico de 1940 a 1985 na Região do Pontal do Paranapanema. Constatou o desenvolvimento da luta de classes cada vez mais acirrada à medida que o capital avançava na agricultura regional no enfrentamento para obter o controle e o domínio territorial. Para Silveira (1990):

Esta classe de pequenos agricultores que ao longo de todo o processo de desenvolvimento econômico, isto é, desde a ocupação da região até o momento atual, tem a sua dinâmica interna e externa no interior do processo contraditório de desenvolvimento do setor capitalista. Estiveram e estão subordinados à grande propriedade, num primeiro momento como um instrumento para a conquista da terra, pois possibilitou o povoamento e a grilagem das terras devolutas. Depois como mão de obra durante a fase cafeeira, contribuindo desde a formação dos cafezais até a colheita. Já durante a fase da pecuária, na cria do gado e na formação das pastagens. Em todas as fases, estes trabalhadores proporcionaram aos proprietários de terra e/ou capitalistas a possibilidade histórica de não dispêndio de capital para o acesso à terra, formação dos cafezais e agora na formação das pastagens (SILVEIRA, 1990, p.119).

O intercalar desses processos dinâmicos implantados na região deixa explícitas as amarras da privatização e concentração de terras com a manutenção de uma classe capitalista que detém a propriedade da maior parte do território, bem como o controle das atividades econômicas. O campesinato permanece atrelado à essa classe seja por que possui pequena quantidade de terra para explorar, ou na falta dela pelo sistema de parceria e arrendamento, ou ainda, como proletários rurais. 
Essas discussões são importantes para ampliar a compreensão sobre a questão agrária como questão estrutural engendrada pelo sistema capitalista a partir do desenvolvimento regional visando identificar de que maneira o capital vem se expandindo e se apropriando dos recursos naturais, sendo a terra o principal deles. E, fazendo parte da mesma análise, verificar as estratégias do campesinato que continua se desenvolvendo no sistema capitalista, mas procura livrar-se de sua asfixia lutando para manter os seus meios de produção.

\section{Considerações finais}

Tais análises tentaram elucidar duas dimensões importantes para a compreensão da questão agrária e do desenvolvimento regional: que a expansão do capital ainda não se consolidou totalmente nas terras agricultáveis da região e, a tentativa do campesinato que, ao se recriar, constrói barreiras diante do capital para obstaculizar seu avanço. Por conseguinte, os dois elementos da questão agrária - o campesinato e o capital - se renovam simultânea e contraditoriamente, interferindo nas relações sociais e no desenvolvimento regional seja pela disputa territorial, seja pelo debate que emerge das interpretações e de seus significados.

Analisar esses desdobramentos é importante para conhecer a nova dinâmica da questão agrária por meio do avanço contraditório do capital na agricultura regional e a partir dessa compreensão valorizar os processos de transformações sociais para que o desenvolvimento regional deixe de priorizar as dimensões tecnológicas visando exclusivamente a produtividade que podem ser mensuradas economicamente em detrimento das dimensões sociais, humanas e ambientais.

\section{Notas}

${ }^{1}$ www.viacampesina.org.br e www.fetrafsul.org.br.

${ }^{2}$ Vide informações em www.territoriosdacidadania.gov.br

\section{Referências}

CHAYANOV, Alexander V. LA Organizacióne La Unidad Econômica Campesina. Buenos Aires: Ediciones Nueva Vision, 1974.

FELICIANO, Carlos Alberto. Movimento camponês rebelde: a reforma agrária no

Brasil. São Paulo: Contexto, 2006. 
FELICIO, Munir Jorge. Apontamentos para ampliar a compreensão da questão agrária no século XXI. In: Revista da Associação Brasileira de Reforma Agrária $A B R A$, volume 35, Jan/Dez, p. 41-58, Andradina (SP), 2008.

FELICIO, Munir Jorge. Contribuição ao debate paradigmático da questão agrária e do capitalismo agrário. 2011. 214 folhas. Tese (Doutorado em Geografia), apresentada no Programa de Pós-Graduação em Geografia. Universidade Estadual Paulista, campus de Presidente Prudente.

FERNANDES, Bernardo Mançano. MST: formação e territorialização. São Paulo: Hucitec, 1996.

FERNANDES, Bernardo Mançano. Questão Agrária: conflitualidade e desenvolvimento territorial. In: BUAINAIN, Antonio Márcio (org.) Luta pela Terra, Reforma Agrária e Gestão de Conflitos no Brasil. Editora Unicamp, 2008, p. 173224.

GOHN, Maria da Gloria. Teoria dos Movimentos Sociais. São Paulo: Loyola, 1997.

HESPANHOL, Antonio Nivaldo. Políticas Públicas, modernização e crise da agricultura brasileira. In: Revista Faz Ciência, volume 1, no. 1, p. 38-49, Francisco Beltrão, 1997.

KAUTSKY, Karl. A questão agrária. Rio de Janeiro: Laemmert, 1986.

LEITE. José Ferrari. A ocupação do Pontal do Paranapanema. 1981. 256 f. Tese (Livre-Docência), Instituto de Planejamento e Estudos Ambientais da Universidade Estadual Paulista - "campus" de Presidente Prudente.

LUXEMBURG, Rosa. A Acumulação do Capital. São Paulo: Nova Cultural, 1985.

MARTINS, José de Souza. Os camponeses e a política no Brasil Petrópolis: Vozes, 1981.

MARTINS, José de Souza. O poder do atraso. São Paulo: Hucitec, 1994.

MARTINS, José de Souza. Reforma Agrário O Impossível Diálogo São Paulo: Edusp, 2004.

MAZOYER, M. e ROUDART, L. História das agriculturas do mundo: do neolítico à crise contemporânea. Lisboa: Ed. Histórias e Monografias, 1998.

NAVARRO, Zander. Nunca cruzaremos este rio - a estranha associação entre o poder do atraso, a historia lenta e a 'sociologia militante', e o ocaso da reforma agrária no Brasil. In: ENCONTRO ANUAL DA ANPOCS, XXXII, 2008, Caxambu (MG). Anais, Caxambu (MG). 
NAVARRO, Zander. Mobilização sem emancipação - As lutas sociais dos sem-terra no Brasil, In: SANTOS, Boaventura de Sousa (org.) Produzir para viver. Rio de Janeiro: Civilização Brasileira, p. 189-232, 2005.

NEVES, Delma Pessanha. Agricultura familiar: questões metodológicas. Revista ABRA, no 2 e 3, volume 25, maio/dez, p. 21-36, 1995.

NEVES, Delma Pessanha. Agricultura familiar: quantos ancoradouros. In: FERNANDES, B. M., MARQUES, M.I.M., SUZUKI, J.C. (orgs.). Geografia Agrária teoria e poder. São Paulo: Expressão Popular, 2007, p. 211- 270.

OLIVEIRA, Ariovaldo Umbelino de. A Geografia das lutas no campo. $11^{\text {a }}$ edição revista e ampliada. São Paulo: Contexto, 2002.

OLIVEIRA, Ariovaldo Umbelino de. Modo de Produção Capitalista, Agricultura e Reforma Agrária. São Paulo: FFLCH/Labur Edições, 2007.

ORIGUÉLA, Camila Ferracini. Paradigma e metodologia da questão agrária: uma análise das ocupações de terras no Brasil com ênfase para o Pontal do Paranapanema. 2011. 98 f. Monografia de bacharelado. Faculdade de Ciências e Tecnologia, Universidade do Estado de São Paulo, Presidente Prudente.

PAULINO, Eliane Tomiasi. O Limite das Cercas: desdobramentos da apropriação capitalista da terra e as estratégias da exploração familiar em Presidente Prudente. 1997. 228 f. Dissertação (Mestrado em Geografia). Faculdade de Ciências e Tecnologia, Universidade do Estado de São Paulo, Presidente Prudente.

PEDON, Nelson Rodrigo. Movimentos Socioterritoriais: uma contribuição conceitual à Pesquisa Geográfica. 2009. $240 \mathrm{f}$. Tese (Doutorado em Geografia). Faculdade de Ciências e Tecnologia, Universidade do Estado de São Paulo, Presidente Prudente.

PLOEG, Jan. Douwe. Van. Der. Camponeses e Impérios Alimentares Lutas por Autonomia e Sustentabilidade na Era da Globalização. Porto Alegre: UFRGS Editora, 2008.

RAFESTIN, Claude. Por uma geografia do poder. São Paulo: Ática, 1993.

SILVEIRA, Fátima Rotundo de. A recriação capitalista do campesinato (Os camponeses na região de Presidente Prudente). 1990. 249 f. Tese (Doutorado em Geografia). FFLCH- USP, São Paulo.

SABOURIN, Eric. Que política pública para a agricultura familiar no segundo governo Lula? In: Sociedade e Estado, volume 22, nº. 3, Brasília, setembro/dezembro 2007. 